\title{
Seventh International Management Congress
}

$\mathrm{T}$ HE Seventh International Management Congress was held in Washington, D.C., in September last. According to a leaflet, issued to prospective members, a feature of the Congress was to be "the presentation of both American and foreign points of view on the most important aspects of management in relation to social and economic problems".

More than twenty countries sent delegates to the conference, the most notable exception being Soviet Russia, the absence of delegates from which may be regretted since a socialist State has many interesting management problems of its own. Business men were in a majority among the delegates, although there were also many research workers and university representatives, largely from the United States. This is, in itself, an interesting indication of the rapid development of the social sciences in the United States and their contact with the world of production and distribution, and management in general.

More than two hundred papers were presented to the Congress for discussion, covering the fields of administration, production, distribution, personnel, agriculture, and home management. But a great deal of this material was nothing more than propaganda for or against various political regimes. There was much that might have been better said and even more that would have been better not said at all ; though one must concede that many of the contributors may have been misled by the terms of reference which have been quoted.

It would have been well if more of the delegates had written their papers and speeches from the point of view so ably expressed by Lord Leverhulme in an address to the Congress. "We are all conscious," he said, "of the striking disparity between the world's actual consumption of goods and services and the potential powers of production with which science has now endowed mankind. Few of us, on the other hand, accept this situation as the natural and permanent result of the progressive application of science to all departments of our life and culture. We recognize our present troubles to have arisen to a large extent because our progress has been unbalanced and there has been a time lag between technological progress and progress in other departments of human endeavour. We recognize that the danger of our present situation lies not in the increasing impact of science on our lives, but in the uneven incidence of this impact. While productive efficiency has increased and continues to advance with bewildering rapidity, we destroy much of the possible advantage to be derived from this progress by the methods we adopt in our distributive machinery and in our dealings with our fellow men. As long as we continue to believe that the problem must be solved by the artificial creation of scarcity through restricting production, so long will the situation continue to grow worse."

The reason why the above approach to management problems was largely absent from the Congress was best expressed by Dr. H. C. Link in an excellent speech on the psychological foundations of management. "A few weeks ago", he said, "the steel companies announced their annual appropriations of about ten million dollars for research into the development and behaviour of steel. This is more in one year than has been spent in the entire history of psychology, since it became a quantitative science, for research into the development and behaviour of personality. . . What are the results ? One of the most obvious is this; while denying the possibilities of a science of man, almost every manager regards himself as an authority on human nature. Managers who consider themselves ignorant of the dynamics of machines nevertheless consider themselves, with no more scientific study, authorities on the dynamics of the emotions of man. The result has been a continuous conflict of personal opinions, and the triumph of might rather than right, of expediency rather than truth."

It can be very easily understood from this, that a management conference is handicapped by the fact that there is so little concrete data to talk about and discuss, and wherever such a state of affairs exists there are bound to be numerous papers about nothing at all. A great deal of the general addresses were nothing more than orations on the merits of private enterprise, re-echoing, time and time again, old, familiar, and outworn phrases. In view of the fact that the Congress included delegates from the co-operatives of many countries and also from labour organizations, such speeches were thoroughly misplaced, and although the delegates listened with good humour, many of them must have felt that they indicated the presence of a terrible number of guilty consciences. But in spite of this, it was encouraging to find quite a few of the delegates expressing the view that managerial problems ought to be studied strictly from the professional aspects, and that their study is obscured by political contentions, selfish motives and class conflicts. A plea from Major Urwick that management problems should be approached from the scientific rather than from the nationalistic attitude was passed by without much consideration.

On the whole, it may be said that neither the papers presented at the general sessions nor the subsequent discussion were particularly noteworthy. Some of the papers dealt with management problems, but the majority were concerned only with technological procedures. The agricultural section, which stood in a class by itself in so far as quality was concerned, discussed a total of thirty-seven papers, of which seventeen dealt with purely technical matters such as the control of plant diseases, soil erosion, etc. Prof. John D. Black in some concluding remarks to this section said that "it is not difficult for one who has had contact with our agricultural colleges to understand how management in agriculture has come to be discussed in this segmentary way. . . . No satisfactory co-ordination of technology and social science has been achieved."

With regard to the other sections, very little can be said. The distributors spent three days discussing problems such as sales promotions, touch appeal, branded goods, and, more often still, arguing about the meaning of the terms they were using. The consumer was in the forefront of all such debates, though he was talked about more as a victim than 
as one who is to be served. 'The Swedish co-operators, who had much to contribute to the general theme of improving on our present methods of distribution, as also some of the other foreign visitors, were given little opportunity or encouragement to take an active part in the discussions.

Similar remarks could be made about the other sections.

During the meeting "The American Society for the Advancement of Management" held a dinner for those attending the Congress, at which various New Deal administrators were invited to speak. This was the only occasion during the week at which the New Deal was mentioned, other than in derogatory terms. From the point of view of the visitors from overseas, this was the most instructive meeting, for here alone was it possible to learn about things which they did not understand, and to hear things which had been heard many times before.

\title{
Research and Development in Glass Technology
}

\author{
New Laboratories at St. Helens
}

$\mathrm{T}$ HE new researeh laboratories of Messrs. Pilkington Brothers, Ltd., at St. Helens, opened by Sir William Bragg on October 5, represent a yet further stage in the scientific development of glass technology in which such striking progress has been made during the post-War years. At the luncheon before the opening ceremony, Lord Cozens-Hardy, chairman of the company, reviewed its progress ; the firm has carried out glass manufacture at St. Helens for more than a century, the first works chemist having been appointed in 1844 and the analytical laboratory dating from 1869 . He referred to the high level of glass making which had been attained by chemical and technical skill in the early years of the century. Not only was it known what types of ingredients and proportions were necessary to obtain high-quality glass, but also very considerable strides had been made in manufacturing refractories to stand up well to high-temperature conditions without being unduly attacked by the molten glass. Since the Great War, however, the manufacture of glass has largely been mechanized, necessitating very close control of the compositions and the temperature at which glass is melted and worked. Out of the experimental investigations necessitated by this position there has grown a technical development department.

Towards the end of 1936, the directors of Messrs. Pilkington Brothers decided to supplement this work by forming a research laboratory, closely associated with which was to be a general analytical laboratory for control of the Company's products. The new research department is intended to function in the more academic field of science and will, it is expected, frequently be responsible for fundamental work on first principles. The problems with which the new laboratories will be confronted fall into seven categories, covering the melting of glass, the study of refractories, the processing of glass, uses of glass, the properties of glass, methods of testing glass, and miscellaneous matters such as the production of mirrors to withstand rigorous weathering and temperature conditions, etc. Lord Cozens-Hardy referred to further advances in glass manufacture which are approaching completion, by which a ribbon of glass flowing out of a tank is passed successively through the annealing process and through a grinding and polishing machine which treats both sides simultaneously, the whole machine being more than 1,000 feet long. Its use, it is believed, will once more completely revolutionize the manufacture of plate glass.

Before cutting a glass silk ribbon across the doorway of the new laboratory, Sir William Bragg referred to the way in which in recent years the use of $\mathrm{X}$-ray methods has elucidated the ultimate structure of glass with some approach to completion. The remarkable net-like structure thus revealed has laid the founda. tion for a wholly new attempt to relate the physical and other properties of glass with its chemical constitution. This fuller understanding of the constitution of glass has led to further control over manufacturing methods.

The new laboratories have been built to the design of Mr. Herbert J. Rowse, who also designed the United Kingdom Government Pavilion at the Glasgow Exhibition. Together with the equipment, the cost of

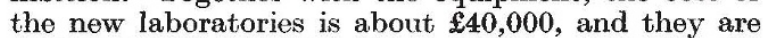
designed to house the director of research, Dr. $H$. Moore, and a staff of forty-seven, including fifteen to twenty university graduates and about twenty-five qualified technical assistants. The laboratories are designed essentially to meet individual requirements, and a novel feature is the use of glass bricks for the internal corridor walls. Most of the physical laboratories are devoted to special instruments or special testing processes, and they include an X-ray laboratory with a fully automatic X-ray apparatus for the identification of crystals and the determination of the viscosity of glass. Other laboratories are specially equipped for thermal expansion measurements, the determination of refractive index and hardness, the measurement of the bending of loaded glass beams, flatness testing and optical work. Among the equipment of the latter is a photometer head integrating sphere for measuring the transmission of light through opaque glass and a Babinet strain viewer. An annexe to the laboratory is devoted to hightemperature work on refractories, glass melting and toughening. Among the apparatus exhibited was a stirring test designed by a member of the staff for comparing the merits of different materials for the construction of tank surfaces. In this apparatus five fingers of these various materials, fixed into a flat circular plate, are rotated vertically in a bath of molten glass at $1,500^{\circ}$.

The main block of the research laboratories includes a large analytical laboratory and laboratories for general chemical research and organic research. In 